\title{
Front Matter: Volume 7950
}

, "Front Matter: Volume 7950," Proc. SPIE 7950, Complex Light and Optical Forces V, 795001 (9 March 2011); doi: 10.1117/12.890424

SPIE. Event: SPIE OPTO, 2011, San Francisco, California, United States 


\section{PROCEEDINGS OF SPIE}

\section{Complex Light and Optical Forces $V$}

David L. Andrews

Enrique J. Galvez

Jesper Glückstad

Editors

26-27 January 2011

San Francisco, California, United States

Sponsored and Published by

SPIE

Volume 7950 
The papers included in this volume were part of the technical conference cited on the cover and title page. Papers were selected and subject to review by the editors and conference program committee. Some conference presentations may not be available for publication. The papers published in these proceedings reflect the work and thoughts of the authors and are published herein as submitted. The publisher is not responsible for the validity of the information or for any outcomes resulting from reliance thereon.

Please use the following format to cite material from this book:

Author(s), "Title of Paper," in Complex Light and Optical Forces V, edited by David L. Andrews, Enrique J. Galvez, Jesper Glückstad, Proceedings of SPIE Vol. 7950 (SPIE, Bellingham, WA, 2011) Article CID Number.

ISSN 0277-786X

ISBN 9780819484871

Published by

SPIE

P.O. Box 10, Bellingham, Washington 98227-0010 USA

Telephone +1 3606763290 (Pacific Time) · Fax +1 3606471445

SPIE.org

Copyright (C) 2011, Society of Photo-Optical Instrumentation Engineers

Copying of material in this book for internal or personal use, or for the internal or personal use of specific clients, beyond the fair use provisions granted by the U.S. Copyright Law is authorized by SPIE subject to payment of copying fees. The Transactional Reporting Service base fee for this volume is $\$ 18.00$ per article (or portion thereof), which should be paid directly to the Copyright Clearance Center (CCC), 222 Rosewood Drive, Danvers, MA 01923. Payment may also be made electronically through CCC Online at copyright.com. Other copying for republication, resale, advertising or promotion, or any form of systematic or multiple reproduction of any material in this book is prohibited except with permission in writing from the publisher. The CCC fee code is 0277-786X/11/ \$18.00.

Printed in the United States of America.

Publication of record for individual papers is online in the SPIE Digital Library.

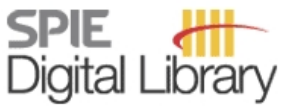

SPIEDigitalLibrary.org

Paper Numbering: Proceedings of SPIE follow an e-First publication model, with papers published first online and then in print and on CD-ROM. Papers are published as they are submitted and meet publication criteria. A unique, consistent, permanent citation identifier (CID) number is assigned to each article at the time of the first publication. Utilization of CIDs allows articles to be fully citable as soon they are published online, and connects the same identifier to all online, print, and electronic versions of the publication. SPIE uses a six-digit CID article numbering system in which:

- The first four digits correspond to the SPIE volume number.

- The last two digits indicate publication order within the volume using a Base 36 numbering system employing both numerals and letters. These two-number sets start with 00, 01, 02, 03, 04, $05,06,07,08,09,0 A, 0 B \ldots 0 Z$, followed by 10-1Z, 20-2Z, etc.

The CID number appears on each page of the manuscript. The complete citation is used on the first page, and an abbreviated version on subsequent pages. Numbers in the index correspond to the last two digits of the six-digit CID number. 


\section{Contents}

vii Conference Committee
ix Introduction

SESSION 1 OPTICAL ANGULAR MOMENTUM I

795003 Angular momentum of light revisited: spin-orbit interactions in free space (Invited Paper) [7950-02]

K. Y. Bliokh, National Univ. of Ireland, Galway (Ireland); M. A. Alonso, Univ. of Rochester (United States) and Aalto Univ. (Finland); E. A. Ostrovskaya, The Australian National Univ. (Australia)

795004 Evolution of orbital angular momentum entangled bi-photon, propagating through a turbulent atmosphere [7950-03]

F. S. Roux, CSIR National Laser Ctr. (South Africa)

\section{SESSION 2 OPTICAL MANIPULATION I}

795006 Development of a two-photon polymerization and optical tweezers microscope for fabrication and manipulation of microstructures [7950-05]

N. Ingle, S. K. Mohanty, The Univ. of Texas at Arlington (United States)

795007 Optical vortex singularities and atomic circulation in evanescent waves [7950-06]

V. E. Lembessis, New York College (Greece); D. L. Andrews, Univ. of East Anglia, Norwich (United Kingdom); M. Babiker, The Univ. of York (United Kingdom); S. Al-Awfi, Taibah Univ. (Saudi Arabia)

795008 Hybrid optical transport trap: loading and unloading of microscale objects using a microfabricated optical fiber into optical tweezers [7950-07]

N. Cardenas, The Univ. of Texas at Arlington (United States); Y. N. Mishra, The Univ. of Texas at Arlington (United States) and Cochin Univ. of Science \& Technology (India);

S. K. Mohanty, The Univ. of Texas at Arlington (United States)

\section{SESSION 3 STRUCTURED LIGHT}

795009 Adaptive shaping of complex pulsed nondiffracting light fields (Invited Paper) [7950-08] M. Bock, S. K. Das, R. Grunwald, Max-Born-Institut für Nichtlineare Optik und Kurzzeitspektroskopie (Germany)

7950 0A Complex light with optical singularities induced by nanocomposites [7950-09] V. V. Ponevchinsky, Institute of Physics (Ukraine); A. I. Goncharuk, F. D. Ovcharenko Institute of Biocolloidal Chemistry (Ukraine); S. V. Naydenov, L. N. Lisetski, Institute for Scintillation Materials (Ukraine); N. I. Lebovka, F. D. Ovcharenko Institute of Biocolloidal Chemistry (Ukraine); M. S. Soskin, Institute of Physics (Ukraine) 
$7950 \mathrm{OB}$ Measuring complex pulses with time-bandwidth products exceeding 65,000 using multiple-delay crossed-beam spectral interferometry [7950-10]

J. Cohen, Georgia Institute of Technology (United States); P. Bowlan, Max-Born-Institute (Germany); V. Chauhan, P. Vaughan, R. Trebino, Georgia Institute of Technology (United States)

7950 OD Fermionic transformation rules for spatially filtered light beams in conical refraction [7950-12]

Y. V. Loiko, Univ. Autònoma de Barcelona (Spain); M. A. Bursukova, Conerefringent Optics SL (Spain); T. K. Kalkanjiev, Univ. Autònoma de Barcelona (Spain); E. U. Rafailov, Univ. of Dundee (United Kingdom); J. Mompart, Univ. Autònoma de Barcelona (Spain)

\section{SESSION 4 OPTICAL ANGULAR MOMENTUM II}

7950 OE Measuring the orbital angular momentum of light (Invited Paper) [7950-13] M. J. Padgett, M. Lavery, Univ. of Glasgow (United Kingdom); G. Berkhout, Leiden Univ. (Netherlands); J. Courtial, Univ. of Glasgow (United Kingdom); M. Beijersbergen, Leiden Univ. (Netherlands)

7950 OF Orbital angular momentum induced beam shifts [7950-14] N. Hermosa, M. Merano, Leiden Univ. (Netherlands); A. Aiello, Max Planck Institute for the Science of Light (Germany); J. P. Woerdman, Leiden Univ. (Netherlands)

$7950 \mathrm{OH} \quad$ Raman optical activity by light with spin and orbital angular momentum [7950-16] G. Milione, J. Secor, G. Michel, S. Evans, R. R. Alfano, The City College of the City Univ. of New York (United States)

7950 Ol Measurement of angular momentum flux in optical tweezers (Invited Paper) [7950-34] H. Rubinsztein-Dunlop, T. Asavei, D. Preece, A. B. Stilgoe, N. R. Heckenberg, T. A. Nieminen, The Univ. of Queensland (Australia)

\section{SESSION 5 THEORETICAL ADVANCES}

7950 0J Scalar Goos-Hänchen shift for Robin boundary conditions (Invited Paper) [7950-17] M. R. Dennis, J. B. Götte, Univ. of Bristol (United Kingdom)

7950 OK Cylindrical vector beam generation from a multi elliptical core optical fiber [7950-18] G. Milione, H. I. Sztul, The City College of the City Univ. of New York (United States); D. A. Nolan, Corning Inc. (United States); J. Kim, The City College of the City Univ. Of New York (United States); M. Etienne, J. McCarthy, J. Wang, Corning Inc. (United States); R. R. Alfano, The City College of the City Univ. of New York (United States)

7950 OL Structured light, transmission, and scattering [7950-19]

D. L. Andrews, Univ. of East Anglia Norwich (United Kingdom)

7950 OM Engineering Dresselhaus spin-orbit coupling for cold atoms in a double tripod configuration [7950-20]

G. Juzeliūnas, J. Ruseckas, Vilnius Univ. (Lithuania); D. L. Campbell, I. B. Spielman, Joint Quantum Institute (United States) 
795000 Developing our next generation BioPhotonics Workstation (Invited Paper) [7950-22]

A. Bañas, D. Palima, S. Tauro, J. Glückstad, Technical Univ. of Denmark (Denmark)

$7950 \mathrm{OP} \quad$ Optical waveguide trapping forces on hollow glass spheres [7950-23]

P. Løvhaugen, B. S. Ahluwalia, O. G. Hellesø, Univ. of Tromsø (Norway)

7950 OQ Functionalized 2PP structures for the BioPhotonics Workstation [7950-24]

T. Matsuoka, M. Nishi, M. Sakakura, K. Miura, K. Hirao, Kyoto Univ. (Japan); D. Palima,

S. Tauro, A. Bañas, J. Glückstad, Technical Univ. of Denmark (Denmark)

SESSION 7 OPTICAL PHASE PROPERTIES

7950 OR Optical sculpting: trapping through disorder and transfer of orbital angular momentum (Invited Paper) [7950-25]

T. Cizmar, M. Mazilu, H. Dalgarno, P. Ashok, F. Gunn-Moore, K. Dholakia, Univ. of St. Andrews (United Kingdom)

7950 OS Geometric phase associated with transformations of cylindrical vector beams [7950-26] G. Milione, H. I. Sztul, R. R. Alfano, The City College of the City Univ. of New York (United States)

7950 OT Evolution of optical vortex distributions in stochastic vortex fields [7950-27]

F. S. Roux, CSIR National Laser Ctr. (South Africa)

7950 OU Probing quantum cores of optical vortices with atoms [7950-28]

J. B. Götte, M. R. Dennis, Univ. of Bristol (United Kingdom)

\section{SESSION 8 OPTICAL FORCES AND TRAPPING}

7950 OW Microparticle sorting using a slot waveguide splitter [7950-30]

S. Lin, K. B. Crozier, Harvard Univ. (United States)

7950 OX Optical trapping efficiencies from $\boldsymbol{n}$-phase cylindrical vector beams [7950-31]

B. J. Roxworthy, Lab. for Photonics Research of Bio/nano Environments (United States) and Univ. of Illinois at Urbana-Champaign (United States); K. C. Toussaint, Jr., Lab. for Photonics Research of Bio/nano Environments (United States), Univ. of Illinois at Urbana-Champaign (United States), and Beckman Laser Institute for Advanced Science and Technology (United States)

7950 oY Characterization of optical trap for metallic particles using external magnetic field [7950-32] V. S. Jadhav, W. Sayyad, Univ. of Pune (India) and Anna Univ. (India); G. R. Kulkarni, Univ. of Pune (India); B. M. Jaffar Ali, Pondicherry Univ. (India) 
POSTER SESSION

$79500 Z$ Hybrid vector beam generation [7950-33]

G. Milione, S. Evans, R. R. Alfano, The City College of the City Univ. of New York (United States)

Author Index 


\title{
Conference Committee
}

\author{
Symposium Chair
}

Liang-Chy Chien, Kent State University (United States)

Symposium Cochairs

Klaus P. Streubel, OSRAM GmbH (Germany)

E. Fred Schubert, Rensselaer Polytechnic Institute (United States)

Program Track Chair

Zameer U. Hasan, Temple University (United States)

Conference Chair

David L. Andrews, University of East Anglia Norwich (United Kingdom)

Conference Cochairs

Enrique J. Galvez, Colgate University (United States)

Jesper Glückstad, Technical University of Denmark (Denmark)

Program Committee

Nicholas P. Bigelow, University of Rochester (United States)

Shu-Chun Chu, National Cheng Kung University (Taiwan)

Kishan Dholakia, University of St. Andrews (United Kingdom)

Wolfgang A. Ertmer, Leibniz Universität Hannover (Germany)

Jean-Marc R. Fournier, Ecole Polytechnique Fédérale de Lausanne (Switzerland)

David G. Grier, New York University (United States)

Rüdiger Grunwald, Max-Born-Institut für Nichtlineare Optik und Kurzzeitspektroskopie (Germany)

Gerard Nienhuis, Leiden University (Netherlands)

Miles J. Padgett, University of Glasgow (United Kingdom)

Monika A. Ritsch-Marte, Medizinische Universität Innsbruck (Austria)

Halina H. Rubinsztein-Dunlop, The University of Queensland (Australia)

Marat S. Soskin, Institute of Physics (Ukraine)

Grover A. Swartzlander, Jr., Rochester Institute of Technology (United States)

Juan P. Torres, Instituto de Ciencias Fotónicas (Spain) 
Ewan M. Wright, College of Optical Sciences, The University of Arizona (United States)

\section{Session Chairs}

1 Optical Angular Momentum I

David L. Andrews, University of East Anglia Norwich (United Kingdom)

2 Optical Manipulation I

Jesper Glückstad, Technical University of Denmark (Denmark)

3 Structured Light

Miles J. Padgett, University of Glasgow (United Kingdom)

$4 \quad$ Optical Angular Momentum II

Mark R. Dennis, University of Bristol (United Kingdom)

5 Theoretical Advances

Gabriel Molina-Terriza, Macquarie University (Australia)

6 Optical Manipulation II

Marat S. Soskin, Institute of Physics (Ukraine)

$7 \quad$ Optical Phase Properties

Grover A. Swartzlander, Jr., Rochester Institute of Technology (United States)

$8 \quad$ Optical Forces and Trapping

Kishan Dholakia, University of St. Andrews (United Kingdom)

David L. Andrews, University of East Anglia Norwich (United Kingdom) 


\section{Introduction}

It has been six years since the launch of the conference whose proceedings follow. Starting from lowly beginnings under the auspices of a growing Photonics West congress held in San Jose and working with the initial title Nanomanipulation with Light, this conference has evolved with remarkable speed into an established fixture in the international conference calendar, quickly becoming a recognized forum for reporting progress in this highly active and rapidly advancing field of optical physics. In a very real sense, the growth and development of the conference itself reflects an intensification of research activity in the subject area.

The specific linkage of optical forces with complex beams is once again a distinctive motif in many of the studies reported this year, studies which exploit the richly structured potential surfaces generated by optical beams of unusual structure. It is now well known that optical singularities link inextricably with phase vortices, and experimental applications frequently make use of the associated angular momentum to rotate optically trapped particles. The scope for such optical manipulation accommodates particles as diverse as cold atoms and biological micro, and in the latter case the pace of development is such that commercialization is now in view.

If this connection of complex light with optical force is regarded as a middle ground for the conference, the full remit nonetheless extends over a much wider range. Indeed, these proceedings include many examples of optical nanomanipulation with conventional optical modes. Some of the emerging microfluidic and particle sorting applications are achieving results that, not long ago, would have seemed entirely fanciful. Even the capacity to directly exploit radiation pressure is now leading to new possibilities for producing optical lift. Moreover, advances in nanofabrication are allowing the development of exquisitely structured components, tailored to rotate under the influence of light, fuelling the potential for future developments.

Research studies that specifically address the properties of phase-structured and singular beams, such as those of Bessel and Laguerre-Gaussian form, commonly engage deep fundamental principles whose theoretical constructs also remain under active development, notably those concerned with the orbital angular momentum of light. As the theory is being consolidated, there is an increasing focus on devising methods to unambiguously identify beams with unknown angular momentum content, and notable advances are being made. Here, the 
associated issues have a significant bearing on the viability of schemes for quantum information transmission. This is a rich ground for theoretical work and it is highly encouraging to see an active engagement between theoreticians and experimentalists. It is, indeed, another distinctive feature of this conference.

The term 'complex light' encompasses more than just light beams with exotic wave-front structures. There is considerable progress in the devising of optical elements that can produce such structures and there are close links to the polarization layout in beams of radial and azimuthal polarization, also associated with 'hollow' beams. Recognition of these links has paved the way for the novel imaging applications now being reported. Cases of temporal, rather than spatial, structure are also rising in prominence, through studies where active phase masks and spatial light modulators are deployed. Even laser filamentation, a phenomenon that first came into prominence twenty years ago, largely as a curiosity characterized by its unpredictability, has now been brought under control to the extent that bundles of co-propagating beam filaments can assist in the cause of divergence-free propagation.

Bringing these papers to the proceedings provides a welcome opportunity to thank all the contributors. I very gladly acknowledge the support of my very able co-chairs Kiko Galvez and Jesper Glückstad. Together we also express sincere gratitude to the members of our highly active and supportive Program Committee, whose sterling work underpins the success of this conference each year. We remain indebted to the SPIE staff at every level, for reliable management and production processes, achieved with customary hallmark professionalism.

David L. Andrews 